\title{
ATIVIDADE FÍSICA E SAÚDE MENTAL: RELATO DE VIVÊNCIA
}

Originais recebidos em: 30/12/2010

Aceito para publicação em: 11/01/2012

Fernando Teixeira dos Santos

Universidade Federal de Uberlândia fernando@edf.ufu.br

\section{Fernanda de Oliveira Rodrigues Lopes Francielle Meira Mota Lísia Arantes Rodrigues Patrícia Silvestre de Freitas Tamires Fernandes de Oliveira Universidade Federal de Uberlândia}

\section{Resumo}

Este trabalho trata-se do relato das experiências vivenciadas durante a disciplina Prática Pedagógica e Diversidade Humana (PIPE 4), realizada na Universidade Federal de Uberlândia (UFU), no curso de Educação Física, e tem por objetivo apresentar as experiências vivenciadas nessa disciplina, baseando-se no comportamento e interação entre o grupo e os pacientes de um projeto de extensão que atende pacientes com transtornos mentais. Para isso, utilizou-se uma metodologia qualitativa, caracterizando um estudo de caso descritivo, no qual se buscou mostrar, por meio de relatos de estagiários e monitores do projeto de extensão Atividade Física e Saúde Mental (AFISAM), como a Educação Física pode contribuir para a qualidade de vida de pessoas com transtornos mentais. Portanto, este trabalho foi resultado de relatos de vivências de estagiários e monitores do projeto ao longo de um semestre letivo. O projeto é composto de monitores, alunos e professores do curso de Educação Física, além de psicólogos e assistentes sociais dos CAPSs. As atividades foram ministradas por acadêmicos do curso de Educação Física, supervisionados por uma docente, coordenadora do programa, e buscaram propiciar melhora na qualidade de vida dos pacientes que apresentam distúrbios mentais, tais como embotamento afetivo, humor deprimido, ansiedade, compulsão alimentar e neuroticismo. Conclui-se que essa prática influiu no comportamento dos pacientes, sugerindo que pode haver melhoras na qualidade de vida e no convívio social, além de evidenciar a necessidade de discussões acerca das possibilidades da Educação Física no contexto da saúde mental.

Palavras-chave: Atividade física; Educação Física; Saúde mental; Vivências.

$$
\begin{aligned}
& \text { PHYSICAL ACTIVITY AND MENTAL } \\
& \text { HEALTH: REPORT OF EXPERIENCE }
\end{aligned}
$$

\begin{abstract}
This paper deals with is the account of experiences during the course Pedagogical Practice and Human Diversity - PIPE 4 developed at Federal University of Uberlandia in Physical Education course, and aims to present the experiences in the discipline PIPE 4 , based on the behavior and interaction between the group and patients. For this, we used a qualitative methodology, featuring a descriptive case study, which sought to show how physical education can contribute to the quality of life of people with mental disorders through reports of trainees and monitors the AFISAM Project. Therefore, this work was the result of reports of experiences of trainees and monitors the project over a semester. The team is composed of monitors and students of Physical Education, as well as psychologists and social workers. Activities are conducted by students of Physical Education, supervised by a professor, the program coordinator, seeking to provide improved quality of life of patients have mental disorders, such as blunted affect, depressed mood, anxiety, binge eating and neuroticism. It is concluded that this practice influenced in the behavior of patients, suggesting that there may be improvements in quality of life and social life, and also highlights the need for discussions about the possibilities of physical education in the context of Mental Health.
\end{abstract}

Keywords: Physical Activity; Physical Education; Mental Health; Experiences. 


\section{INTRODUÇÃO}

De acordo com a Organização Mundial da Saúde, o conceito de saúde é inerente a um estado de bem-estar físico, mental e social, e não apenas à ausência de doenças. Ressalta-se, por isso, a importância dos diversos profissionais das áreas afins a práticas que proporcionam um bem-estar psicológico e social, e não apenas benefícios fisiológicos, no intuito de produzir saúde e qualidade de vida (MIELNIK, 1979; RIBEIRO, 1999).

É preciso lembrar ainda que o conceito de saúde mental implica o de saúde integral: devemos considerar a saúde física e o ajuste social, além da saúde mental. Só do ponto de vista global é que podemos aceitar o conceito de ajustamento adequado, o qual abrange os fatores físicos, psíquicos, interpessoais, sociais e culturais (RIBEIRO, 1999).

No Brasil, calcula-se que atualmente há mais de 30 milhões de pessoas que sofrem algum transtorno mental que ocasionam alguma sobrecarga na família ou sociedade com a qual convive a pessoa que possui transtorno. (GONÇALVES, 2009).

Diante disso, há várias formas de tratamento para pessoas com transtornos mentais, algumas delas bem distintas das outras: há instituições que tratam de saúde mental que são contra a internação e outras atividades e há instituições que são a favor.

Foucault (2007), por exemplo, cita o contexto histórico do tratamento à saúde mental, na perspectiva de uma cultura médica tradicional, na qual se via o corpo do paciente como mero objeto de intervenção clínica, sendo a internação um modelo de tratamento excludente e opressor. Esse fator presume a necessidade de outras formas e intervenções profissionais para o tratamento da saúde mental, entre elas, a prática sistematizada de atividades físicas, por meio do profissional da Educação Física. Nesse sentido, a área da Educação Física, mundialmente, tem se preocupado com o atendimento a essa clientela e com a preparação de recursos humanos para atuarem nessa área do conhecimento (WACHS, 2008).

A Educação Física tem aceitado o desafio de inserir no tratamento das pessoas com transtornos mentais os valores corporais do movimento, contribuindo assim para o desenvolvimento motor e para evidenciar a singularidade de cada indivíduo e suas possibilidades com o corpo.

Nessa perspectiva, a Universidade Federal de Uberlândia se destaca no cenário nacional como uma instituição preocupada com a questão dessas pessoas, pois utiliza 
algumas práticas de atividades físicas e esportes como instrumentos importantes na contribuição para a inserção social e reabilitação de grupos especiais, bem como o tratamento à saúde mental, através do projeto de extensão Atividade Física e Saúde Mental (AFISAM).

O Projeto AFISAM tem como objetivo estimular a atividade física às pessoas que têm transtornos psíquicos. Nesse sentido, pacientes do Centro de Convivência e Centros de Atenção Psicossocial (CAPS), do município de Uberlândia/MG, participam de um programa de atividades físicas por meio de ações conjuntas com os graduandos e profissionais de Educação Física da Universidade Federal de Uberlândia, que ministram a prática das aulas de atividade física aos pacientes atendidos no projeto. Esse programa é realizado no próprio campus universitário e conta com o apoio de docentes e discentes participantes do projeto de extensão. Este trabalho tem como objetivo aumentar a autoestima, a motivação e o bem-estar e, por consequência, contribuir para a melhoria na qualidade de vida dos pacientes, bem como promover a inserção social através de ações que possibilitem o acesso ao esporte e ao lazer.

As aulas propostas pelo AFISAM têm uma hora de duração, são realizadas em dois dias da semana e atendem a crianças e adultos em turmas distintas. Esse programa tem propostas de atividades físicas diversas que fazem parte do projeto terapêuticas dos pacientes, os quais são acompanhados por psicólogos e assistentes sociais, além de monitores, estagiários e docentes da educação física. As atividades são desenvolvidas no campus Educação Física da Universidade Federal de Uberlândia (FAEFI-UFU). Os alunos do curso de Educação Física participantes do AFISAM fazem parte da disciplina Prática Pedagógica e Diversidade Humana (PIPE 4), componente curricular que compreende a vivência com grupos especiais. Os monitores e alunos da disciplina PIPE $4^{1}$ são responsáveis por realizar, ministrar e instruir as aulas de práticas de atividades físicas, sendo os monitores acadêmicos que já passaram anteriormente por essa disciplina. Estes orientam os estagiários em relação à montagem dos planos de aula, elaboração de relatórios para avaliação da disciplina e acompanhamento dos estagiários. As atividades, por sua vez, são supervisionadas por uma docente, coordenadora do projeto.

\footnotetext{
${ }^{1}$ No caso deste trabalho e do projeto de extensão, em geral, os alunos desta disciplina também são comumente chamados de "estagiários", devido à disciplina ser caracterizada como uma prática pedagógica e contar com intervenção pedagógica.
} 
Dentre as atividades do AFISAM, relatamos as realizadas com os pacientes adultos de CAPS e de Centros de Convivência que tratam de pacientes com transtornos mentais que envolvem o embotamento afetivo, humor deprimido, ansiedade, compulsão alimentar e neuroticismos em geral, que incluem depressão, desajustamento, vulnerabilidade, entre outros. Denominamos esse grupo de "AFISAM Adulto", pois este projeto também trabalha com pacientes infantis e pacientes que fazem atividades dentro do próprio CAPS e que apresentam transtornos mais graves.

Segundo o Projeto Pedagógico do curso de Educação Física da UFU, a disciplina PIPE 4 tem como objetivo "Conhecer outras realidades educacionais e a implicação metodológica da atividade física para diferentes grupos, que compõem a diversidade humana e ainda, promover a inclusão por intermédio de práticas coletivas." (Disponível em: www.faefi.ufu.br/sites/faefi.ufu.br/files/Anexos/Bookpage/EF_ProjetoPedagogico.pdf) Diante disso, cada grupo vivencia práticas de atividades físicas com grupos e realidades sociais distintas, desenvolvendo, ao final do semestre, um trabalho para apresentar aos demais colegas da disciplina, a fim de compartilhar experiências e relatos, bem como discutir as possibilidades da Educação Física no que se diz respeito aos sujeitos que vivem no contexto de exclusão.

Este artigo se trata, portanto, de um estudo de caso descritivo com metodologia qualitativa, no qual buscamos mostrar como a Educação Física pode contribuir para a qualidade de vida de pessoas com transtornos mentais por meio de projetos de extensão de atividades físicas em grupo, bem como apresentar relatos de estagiários e monitores do programa em relação à lida com essa clientela e enaltecer a necessidade de serem discutidas questões pertinentes à Educação Física e à Saúde Mental.

Para tanto, relatamos as experiências e vivências do programa de atividade física ao longo de um semestre letivo, evidenciando as principais dificuldades, potencialidades, contingências e algumas possibilidades metodológicas que foram desenvolvidas no decorrer do programa.

\section{DESENVOLVIMENTO}

Por meio da disciplina PIPE 4, tivemos a vivência com o grupo AFISAM Adulto de agosto de 2010 até o final do segundo semestre letivo. As aulas foram realizadas nas 
segundas e quartas-feiras, das $13 \mathrm{~h}$ às $14 \mathrm{~h}$, no Campus Educação Física da UFU. As atividades consistiram em um programa de atividades físicas que contemplou atividades esportivas e recreativas, empregadas com o propósito de promover uma vida ativa às pessoas com transtornos mentais, pacientes dos CAPSs e do Centro de Convivência, diversificando, então, atividades como musculação, hidroginástica, atividades com bola e exercícios físicos recreativos. Os estagiários conduziam e instruíram as aulas de atividades físicas juntamente com os monitores do projeto.

Num primeiro momento, esperava-se que os pacientes pudessem receber os alunos do curso de graduação (monitores e estagiários) com certa rejeição ou agressividade gerando medo de passar por esta experiência até então desconhecida; porém, essa impressão foi bem diferente da realidade, pois houve um interesse imediato pelas atividades que seriam propostas.

No primeiro contato, fomos apresentados ao grupo pelos monitores do AFISAM, e todos ali presentes nos receberam bem. A partir desse momento, começamos a observar cada paciente, na expectativa de conhecer e entender o comportamento e o transtorno mental que possuem.

Iniciou-se a vivência observando as aulas ministradas pelos monitores. Nessa observação, era preciso fazer um relatório de como as aulas aconteciam descrevendo os objetivos geral e específico e o material utilizado; por fim, era preciso relatar a avaliação do grupo.

Com o passar do tempo, através da atividade física, que por si só promove a interação, tivemos um contato maior com eles, o qual ocorria de forma natural, abrindo espaço para conhecê-los e entendermos suas limitações geradas em decorrência do transtorno mental. Os pacientes que participaram dessa atividade foram encaminhados pelos CAPSs do município de Uberlândia, a fim de realizarem atividades físicas como uma possibilidade de tratamento da saúde mental. Portanto, essa prática era consentida por pacientes e equipes, além de ela ter respaldo médico, visto ser necessário atestado antes de serem iniciadas as atividades. Além disso, é bastante notável a lida com o próximo, pois o convívio social é bastante relevado com aulas e atividades em grupo, sempre respeitando as virtudes e os possíveis limites de cada paciente.

A partir de então, começamos a ministrar as aulas com mais segurança, pois vimos que os alunos aproveitavam o máximo das atividades propostas. No começo houve um 
pouco de receio por talvez não conseguirmos manter o ritmo das aulas que já vinham sendo ministradas pelos monitores e não alcançarmos as expectativas esperadas pelos alunos. Porém, logo na primeira aula ministrada, ficou evidente o reconhecimento tanto pela parte dos monitores quanto pela parte dos alunos na tentativa de equilibrar a primeira aula de forma que ela fosse eficaz para o condicionamento físico e, ao mesmo tempo, lúdica e prazerosa, proporcionando uma influência mútua nesse primeiro momento.

Com a possibilidade de vivência dos alunos do curso de educação física, podem-se observar alguns cuidados na planificação e na aplicação das aulas. De acordo com o desenvolvimento deste trabalho e reflexões em grupo na disciplina PIPE 4, o profissional da educação física deve buscar outras formas de organizar o cuidado em suas aulas com os alunos, devendo planejá-las adequadamente, pois a insistência exagerada em certos aspectos da cultura corporal, como a imposição de atividades práticas ou teóricas que não sejam do agrado dos pacientes, pode gerar falta de interesse, traumatizando-os e tornando problemática a personalidade desses indivíduos. Dessa forma, o objetivo da educação física na melhora ou prevenção de pessoas com algum desvio emocional pode fracassar.

A Atividade física auxilia nas necessidades psíquicas fundamentais, pois transmite, em sua prática, sensação de segurança e aceitação, realização, tolerância, independência, tarefa, plano e liberdade, além de necessidade de adaptação ao grupo (espírito de coletividade), de higiene mental (forma uma personalidade com maturidade) e autocontrole psicológico.

As alunas da disciplina PIPE 4 ministraram aulas de hidroginástica, iniciação ao basquetebol e sessões de terapia corporal. As aulas tinham como objetivos proporcionar: (i) melhora da qualidade de vida; (ii) maior socialização, tanto entre os pacientes quanto os pacientes com as estagiárias; (iii) conhecimento dos diversos esportes, começando pelo basquetebol; e (iv) desenvolvimento da coordenação motora e da resistência física.

Cada aula teve seu(s) objetivo(s) específico(s):

- Hidroginástica - objetiva melhorar a capacidade anaeróbica, a resistência cardiorrespiratória, a resistência e a força muscular e a flexibilidade, proporcionando menor impacto nas articulações, maior esforço nos movimentos e sensação de conforto causada pela água.

- Terapia corporal - oportuniza que a pessoa em formação vivencie de forma lúdica sua expressividade corporal, sendo utilizado o corpo como o próprio 
instrumento. Visa proporcionar autoconhecimento, melhora da autoestima, reconhecimento das suas limitações, desbloqueio de certas resistências, bemestar e relaxamento.

- Iniciação ao basquete - teve como objetivo conhecer e vivenciar esse esporte com os pacientes. Foram trabalhados exercícios que melhoram a coordenação motora, a resistência e a força muscular, o trabalho em equipe, a determinação e a força de vontade.

- Atividades lúdicas - tem como objetivo produzir prazer durante sua execução, divertindo os alunos que as praticavam.

As aulas propostas foram realizadas com a participação de todos, e os pacientes demonstravam interesse e empenho, apesar das dificuldades de realizarem algum exercício específico (tiveram mais dificuldades nos exercícios de coordenação motora). Todos participaram de forma divertida e coletiva, e um passou a conhecer o outro a partir das atividades lúdicas.

\section{CONSIDERAÇÕES FINAIS}

Diante da vivência do PIPE 4, podemos inferir que os resultados foram satisfatórios para o grupo que realizou a atividade. O comportamento dos pacientes nas atividades e suas atitudes tiveram uma melhora significativa no sentido de participação das aulas, no seu bem-estar, no convívio social e interatividade entre aluno e professor. Esses motivos nos levaram a crer que os resultados são benéficos aos pacientes do AFISAM Adulto.

Podemos concluir também que essas experiências e o desenvolvimento deste trabalho contribuíram para os estudos acerca do tratamento de pacientes com transtornos mentais e expõem algumas possibilidades e desafios para trabalhar a questão de saúde mental e atividade física, pois fíca evidente a demanda e o comprometimento de profissionais das áreas de Educação, Educação Física, Psicologia, Enfermagem e área Social, apresentando a necessidade de um trabalho realizado de forma interdisciplinar.

Por fim, considerando que todas as pessoas estão sujeitas a algum sofrimento ansiedade, euforia, tristeza, alegria e os vários nuances da saúde mental — a possibilidade de estudar a saúde mental com a educação física é bastante satisfatória no sentido de várias 
das vivências do comportamento humano permearem práticas corporais, que é o objeto da educação física, como pudemos concluir, ao trabalharmos, neste projeto de extensão, com pessoas que sofrem com transtornos mentais.

\section{REFERÊNCIAS}

COLEMAN, James C. A Psicologia do Anormal e a Vida Contemporânea: Primeiro volume. Tradução de Dante Moreira Leite e Miriam L. Moreira Leite. São Paulo: Livraria Pioneira Editora, 1973

LOBOSQUE, Ana Marta; SOUZA, Marta Elisabeth (org.). Atenção em Saúde Mental. 1. Ed. Belo Horizonte: Secretaria de Estado de Saúde de Minas Gerais, 2006.

MELLO, Alexandre Morais. Psicomotricidade, Educação Física e Jogos Infantis. São Paulo: Ibrasa, 1989.

MIELNIK, Isaac. Desajustes Psico-Emocionais: Noções Preventivas. São Paulo: SESI, 1979.

Projeto Pedagógico do Curso de Graduação em Educação Física. Universidade Federal de Uberlândia, Faculdade de Educação Física: Coordenação do Curso de Graduação em Educação Física.

[Disponível em:

www.faefi.ufu.br/sites/faefi.ufu.br/files/Anexos/Bookpage/EF_ProjetoPedagogico.pdf]

RIBEIRO, Paulo Rennes Marçal. Saúde Mental no Brasil. São Paulo: Editora Arte \& Ciência, 1999.

WACHS, Felipe. Educação Física e Saúde Mental: Uma prática de cuidados emergentes em Centros de Atenção Psicossocial (CAPS). 2008. 145 f. Dissertação (Mestrado em Ciências do Movimento Humano) - Escola de Educação Física, Universidade Federal do Rio Grande do Sul, Porto Alegre, 2008. 